\title{
Ancient Photosynthetic Eukaryote Biofilms in an Atacama Desert Coastal Cave
}

\author{
A. Azúa-Bustos • C. González-Silva • R. A. Mancilla • \\ L. Salas • R. E. Palma • J. J. Wynne • C. P. McKay • \\ R. Vicuña
}

Published online: 7 May 2009

(C) Springer Science + Business Media, LLC 2009

\section{Erratum to: Microb Ecol \\ DOI 10.1007/s00248-009-9500-5}

In the original version of this article, one of the authors of the paper (Dr. Palma) forgot to include one of its affiliations. The complete affiliations are given below.
The online version of the original article can be found at http://dx.doi. org/10.1007/s00248-009-9500-5.

A. Azúa-Bustos $(\bowtie) \cdot$ R. A. Mancilla $\cdot$ L. Salas $\cdot$ R. Vicuña Departamento de Genética Molecular y Microbiología,

Facultad, de Ciencias Biológicas,

Pontificia Universidad Católica de Chile,

Alameda 340,

Santiago, Chile

e-mail: ajazua@uc.cl

C. González-Silva

Departamento de Ciencias Químicas y Farmaceúticas,

Universidad Arturo Prat,

Iquique, Chile

J. J. Wynne

USGS, Southwest Biological Science Center,

and Department of Biological Sciences,

Northern Arizona University,

Flagstaff, AZ 86011, USA
C. P. McKay

NASA-Ames Research Center, MS 245-3,

Moffett Field, CA 94035, USA

A. Azúa-Bustos $\cdot$ R. Vicuña

Millennium Institute for Fundamental and Applied Biology, Santiago, Chile

R. E. Palma

Departamento de Ecología, Facultad de Ciencias Biológicas, Pontificia Universidad Católica de Chile,

Santiago, Chile

R. E. Palma

Centro de Estudios Avanzados en Ecología y Biodiversidad, CASEB, Pontificia Universidad Católica de Chile,

Santiago, Chile 